\title{
Effect of Inhaled Corticosteroid Therapy Step-Down and Dosing Regimen on Measures of Asthma Control
}

\author{
David Price ${ }^{1,2 *}$, Alison Chisholm², Elizabeth V Hillyer ${ }^{2}$, Annie Burden ${ }^{2}$, Julie von Ziegenweidt ${ }^{2}$, Henrik Svedsater ${ }^{3}$ and Peter Dale ${ }^{4}$ \\ ${ }^{1}$ Centre of Academic Primary Care, University of Aberdeen, UK \\ ${ }^{2}$ Research in Real Life, Cambridge, UK \\ ${ }^{3}$ GlaxoSmithKline, Middlesex, UK \\ ${ }^{4}$ HEOR Solutions, London, UK
}

\begin{abstract}
Background: Asthma guidelines recommend stepping down therapy to the lowest dose that maintains asthma control.

Objective: We sought to evaluate the effect of dosing frequency and baseline patient and treatment-related factors on database markers of asthma control after inhaled corticosteroid (ICS) dose step-down.

Methods: This retrospective observational study evaluated primary care patients (4-80 years old) with asthma prescribed twice-daily (BD) ICS ( $n=26,834$ ) or ICS/long-acting $\beta$-agonist (LABA; $n=20,814)$ for $\geq 1$ year before $\geq 50 \%$ step-down in ICS dose, when they were switched to once-daily (QD) or remained on BD therapy. Study endpoints included exacerbations (oral corticosteroid prescription, unscheduled asthma-related hospital attendance, or genera practice consultation for lower respiratory tract infection) and medication adherence.

Results: Significant improvements in most endpoints were recorded during the year after step-down, as compared with the prior year (baseline). The proportion of patients with no exacerbation during the baseline yea vs. the year after step-down was as follows ( $p<0.001$ for all comparisons): QD ICS cohort $(73 \%$ baseline vs. $81 \%$ after step-down); BD ICS cohort (67\% vs. $77 \%$ ); QD ICS/LABA cohort (60\% vs. $64 \%)$; BD ICS/LABA cohort (55\% vs. $65 \%$ ). Adherence improved significantly after step-down for all cohorts, most markedly for QD cohorts; and the average daily ICS dose as consumed by patients was higher for all but the QD ICS/LABA cohort despite the reduction in prescribed dose. Factors predicting loss of asthma control after step-down for patients controlled at baseline in either or both ICS and ICS/LABA populations included obesity, smoking, comorbid rhinitis, comorbid gastroesophageal reflux disease, and, during the baseline year, $\geq 7$ short-acting $\beta$-agonist prescriptions, mean consumed ICS dose of $\geq 800 \mu \mathrm{g} /$ day, and $\geq 4$ primary care consultations.
\end{abstract}

Conclusion: Stepping down therapy is a valid management option and may improve asthma-related outcomes. Some improvements may result from increased adherence, particularly among patients switched to QD therapy.

Keywords: Adherence; Asthma; Controller therapy; Exacerbation; Inhaled corticosteroids; Medication regimen; Step-down

Abbreviations: BD: Twice Daily; BMI: Body Mass Index; ICS: Inhaled Corticosteroid; IQR: Inter Quartile Range; LABA: LongActing $\beta$-Agonist; LTRA: Leukotriene Receptor Antagonist; NSAID: Nonsteroidal Anti-Inflammatory Drug; QD: Once Daily; SABA: ShortActing $\beta$-Agonist

\section{Introduction}

Controller therapy for persistent asthma should be administered at the minimum dose necessary to control symptoms and minimize risk of future exacerbations. For patients whose asthma is well-controlled, asthma management guidelines recommend gradually stepping down therapy to identify the lowest dose needed to maintain asthma control [1-3]. While the guidelines concur on the schedule of step-down (every 3 months), there is little published evidence regarding outcomes after stepping down therapy [1-5].

The time of step-down could be an opportunity to change the frequency of asthma controller administration or to simplify the regimen. Minimizing medication burden and impact of the asthma controller regimen for patients with well-controlled asthma may improve adherence and maintain or even improve treatment outcomes. There is robust evidence for other chronic diseases such as diabetes and HIV/AIDS that reducing the dose frequency can improve medication adherence [6]. For respiratory conditions, however, few studies have rigorously examined adherence in relation to dosing regimen, especially for once-daily versus twice-daily administration, although the findings suggest that complex regimens may result in lower adherence [6]. Recently, in a large pragmatic trial, significantly better adherence rates were recorded with a once-daily rather than twice-daily regimen of mometasone furoate for patients with asthma [7].

The objective of this study was to evaluate the effect of dose frequency and baseline factors predictive of loss of asthma control at the time of inhaled corticosteroid (ICS) dose step-down in a real-life, UK primary care population. We sought to characterize and compare clinical profiles for patients on controller asthma therapy who were stepped down in ICS dose to once-daily (QD) or twice-daily (BD)

*Corresponding author: David Price, Centre of Academic Primary Care University of Aberdeen, Polwarth Building, Foresterhill, Aberdeen, UK, Tel: +44 1224 554588; Fax: +44 1224 550683; E-mail: david@rirl.org

Received November 20, 2012; Accepted December 15, 2012; Published December 19, 2012

Citation: Price D, Chisholm A, Hillyer EV, Burden A, von Ziegenweidt J, et al (2013) Effect of Inhaled Corticosteroid Therapy Step-Down and Dosing Regimen on Measures of Asthma Control. J Aller Ther 4: 126. doi:10.4172/2155-6121.1000126

Copyright: ( 2013 Price D, et al. This is an open-access article distributed under the terms of the Creative Commons Attribution License, which permits unrestricted use, distribution, and reproduction in any medium, provided the original author and source are credited. 
administration; to compare patient profiles between the year before and the year after step-down; and to determine which demographic and baseline characteristics predicted a loss of asthma control during the year after step-down for patients who were well-controlled the prior year.

\section{Methods}

\section{Data sources and patients}

This retrospective observational study was an analysis of clinical data drawn from two primary care databases in the United Kingdom (UK), the General Practice Research Database (GPRD) and the Optimum Patient Care Research Database (OPCRD). The GPRD is now incorporated into the Clinical Practice Research Data link (CPRD) [8] but at the time of our study was managed by the UK Medicines and Healthcare products Regulatory Agency (MHRA) and contained de-identified active medical record data for approximately 5 million patients from 500 primary care practices throughout the UK [9-11]. The OPCRD is a UK respiratory dataset containing anonymized, longitudinal, research-quality clinical records and patient-reported outcome data from practices that subscribe to OPC for respiratory review services; at the time of the study, the OPCRD included 341,000 patients at 176 practices [12]. We analyzed GPRD data from 1991 through June 2007 and OPCRD data from 1990 through 2010, with no overlap in patients between the two databases.

For each eligible patient, we studied a 25 -month period comprising 1 year for patient characterization before ICS dose step-down (on the index date) and a 1-year analysis period that began 1 month after stepdown, thereby to exclude patients who rejected the step-down. Thus, to be included in the study, patients were required to have at least 25 months of continuous data. Eligible patients were those who during the baseline year received, according to physician prescribing instructions, BD controller therapy for asthma-as either ICS monotherapy or ICS plus long-acting $\beta$-agonist (LABA) in separate or combination inhalers-followed on the index date by a prescription for $\geq 50 \%$ reduction (step-down) in ICS dose delivered by the same inhaler device type and pack size as during the baseline year. Patients could be on any ICS dose during baseline and, on the index date, could be stepped down to either BD or QD controller therapy. Prescriptions for separate ICS and LABA inhalers had to be separated by no more than 2 months as an indicator of concurrent prescribing for patients assigned to the ICS/ LABA population.

We studied patients with asthma who were 4-80 years old, including only non-smokers 61-80 years old. To support the asthma diagnosis, patients had to have either a diagnostic code for asthma in the database or to have received two or more prescriptions for asthma therapies at different points in time during the baseline year. In addition, patients had to have evidence of current asthma therapy, defined as receipt of at least two separate prescriptions for asthma controller therapy during the outcome year, including the one at the index date. Patients with any chronic respiratory disease other than asthma at any time were excluded from the study.

\section{Outcome measures and statistical analyses}

We analyzed three composite endpoints derived from database markers of asthma control during both baseline and outcome years. The first was evidence of an exacerbation, which we defined as a prescribed course of oral corticosteroids or an asthma-related hospital attendance or admission, Accident and Emergency (A and E) attendance, or outof-hours attendance (as per American Thoracic Society/European
Respiratory Society recommendations [13]), or a General Practice (GP) consultation for lower respiratory tract infection (LRTI). We defined asthma-related events as all events with a lower respiratory code in the database.

The second key endpoint was no loss of asthma control, which we defined as no exacerbation (as above) and no hospital outpatient department attendance for asthma. A third measure, no loss of asthma control plus limited SABA use, we defined as no loss of asthma control (as above) plus a mean daily SABA dose of albuterol $\leq 200 \mu \mathrm{g} /$ day ( $\leq$ 2 puffs/day) or terbutaline $\leq 500 \mu \mathrm{g} /$ day. We included SABA use as an indicator of asthma symptoms, thus the measure served as a proxy for the Global Initiative for Asthma (GINA) definition of control [2].

Adherence to ICS was calculated from recorded prescriptions in the database as the ratio of the doses contained in prescribed refills to the annual number of doses required by the prescription. The controllerto-total asthma medication ratio was defined as the number of units
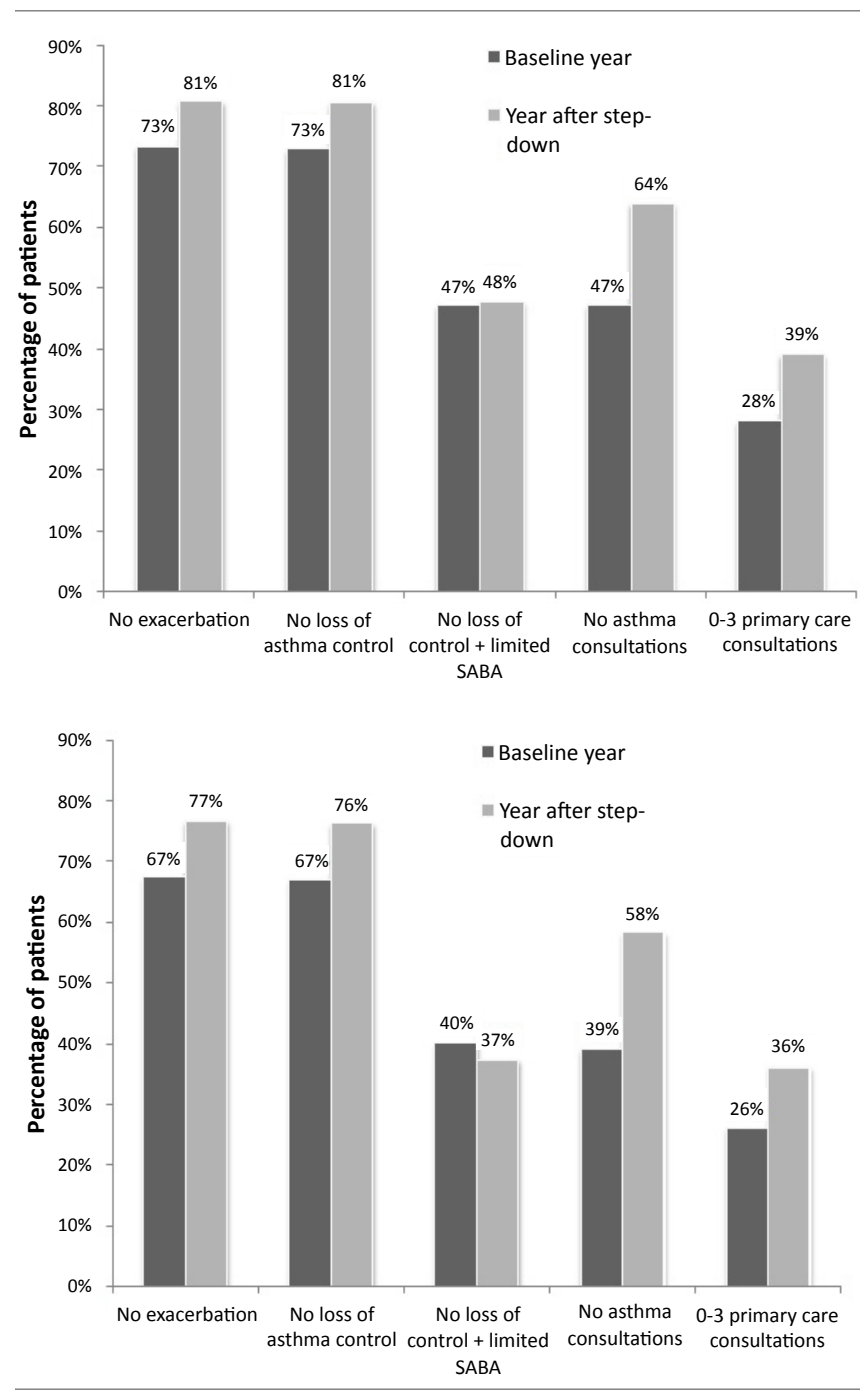

Figure 1: Asthma-related measures for the ICS cohorts during the baseline year and the year after step-down in ICS dose to a once-daily regimen (A) or a twice-daily regimen (B). All measures improved significantly between baseline and post step-down $(p<0.001)$ with the exception of the composite database measure of no loss of asthma control plus limited SABA use, which was comparable in the QD cohort and fell significantly $(p<0.001)$ in the BD cohort. 
of controllers/(units of controllers + units of relievers), denoting ICS as the controller, SABA as the reliever, and one unit as one inhaler $[14,15]$. We also tabulated the use of respiratory resources including prescriptions for asthma therapy (ICS, LABA, SABA, and leukotriene receptor antagonists (LTRAs)), healthcare professional consultations for asthma or LRTI, asthma-related hospitalizations and A and E attendance.

Separate analyses were carried out for each treatment population (ICS and ICS/LABA). Summary statistics were used to characterize the two ICS cohorts (step-down to QD or BD) and the two ICS/LABA cohorts (step-down to QD or BD). Patient profiles were compared within each treatment cohort for the baseline year versus the year after step-down using the Wilcoxon signed rank test (for variables measured on the interval scale), the McNemar test (for binary variables), or the marginal homogeneity test (for ordinal variables) to account for repeated measurements for each patient.

Univariate logistic regression models were used to determine which demographic factors, comorbidities, and baseline characteristics were individually predictive of a loss of asthma control during the year after step-down for all patients with no loss of asthma control during the prior (baseline) year. We selected non-collinear predictive factors and used multivariate logistic regression modeling to determine which factors were predictive of a loss of asthma control, when adjusted for all other non-collinear effects, with the dichotomous status for the no loss of asthma control measure as the dependent variable.

Analyses were performed using SPSS version 18 (IBM UK Ltd, North Harbour Portsmouth, Hampshire, UK), SAS version 9.2 (SAS UK, Marlow, Buckinghamshire, UK), and Microsoft office Excel 2007 (Microsoft UK, Reading, Berkshire, UK). We defined statistically significant results as $\mathrm{p}<0.05$.

\section{Results}

\section{Patients prescribed ICS}

From almost 7 million patients receiving ICS who were included in the GPRD and OPCRD during the study period, we identified 26,834 eligible patients (Supplementary Figure 1) who were prescribed BD ICS during the baseline year and who on the index date were stepped down in dose by $\geq 50 \%$ and either switched to a QD ICS regimen ( $n=941$; $3.5 \%)$ or remained on a BD ICS regimen ( $\mathrm{n}=25,893$; $96.5 \%)$.

There were several significant differences in demographic and baseline year characteristics between the QD and BD cohorts (Table 1 and supplementary table 1). Patients in the QD cohort tended to be older than those in the BD cohort and were less likely to be current smokers or to have taken acetaminophen during the baseline year. Asthma control was better during the baseline year in the QD cohort, as indicated by fewer exacerbations and the percentages of patients who met our composite database measures of asthma control (Table 1). The median daily ICS dose was lower in the QD than the BD cohort at baseline (Table 1). In addition, almost half (48\%) of patients in the QD cohort were stepped down in ICS dose by $>50 \%$, as compared with $22 \%$ of those in the BD cohort; and the index date doses of ICS were lower in the QD cohort (Table 2). The mean index date was 1 year later for patients stepped down to a QD regimen.

During the year after step-down, fewer than $10 \%$ of patients in each cohort were prescribed a second controller: $43(4.6 \%)$ and 1688 (6.5\%) of patients in QD and BD cohorts, respectively, received one or more prescriptions for a LABA; 37 (3.9\%) and 475 (1.8\%), respectively, were prescribed an LTRA. However, the ICS dose was increased for $368(39.1 \%)$ of patients in the QD cohort and 9523 (36.8\%) of those in the $\mathrm{BD}$ cohort. Irrespective of dosing regimen, patients in the ICS cohorts were significantly more likely to have no exacerbations; no GP consultations for LRTI; no asthma consultations, and only 0-3 primary care consultations in the year after step-down in ICS dose, as compared with baseline (Figure 1 and table 3). Moreover, a greater proportion of patients, as compared with baseline, had no loss of asthma control after step-down in both QD and BD cohorts (Figure 1). Adherence improved after step-down, most markedly in the QD cohort, resulting in higher consumed ICS daily dose over the year than during the baseline year (based on prescriptions/year) despite the prescribed step-down in daily ICS dose (Table 3). In both cohorts the median (IQR) number of ICS prescriptions increased from 2 (1-4) during the baseline year to 4 (3-6) during the year after step-down. Median SABA daily doses also increased during the outcome year (Table 3); therefore, the noloss of asthma control measure incorporating limited SABA use did not improve. However, the mean controller-to-total medication ratio improved in both cohorts after step-down, suggesting that patients were not using excessive reliever therapy in place of controller therapy.

Using multiple logistic regression modeling, and considering all significant non-collinear factors identified in the univariate model, we identified several demographic and clinical baseline factors that predicted a loss of asthma control in the year after ICS dose step-down for patients who had no loss of asthma control during the baseline year before step-down (Table 4). We found that female patients, obese patients, smokers, and patients with a recorded GERD diagnosis and/ or receiving therapy for GERD were more likely to lose asthma control. Moreover, patients with an earlier step-down date, or who, during the baseline year, received seven or more SABA prescriptions or had more than three primary care consultations were more likely to lose control. The time of diagnosis or first evidence of asthma was collinear with the step-down year and could replace it in the model. Similarly, the number of SABA prescriptions was collinear with the number of ICS prescriptions and the number of asthma prescriptions; either of the latter variables could replace SABA prescriptions in the model. The dosing regimen after step-down (QD vs. BD) was not a predictive factor for loss of asthma control.

\section{Patients prescribed ICS/LABA}

We identified 20,814 patients who were prescribed BD ICS/LABA during the baseline year and were switched after ICS dose step-down to a QD regimen $(n=505 ; 2.4 \%)$ or remained on a BD regimen $(n=20,309$; 97.6\%; Supplementary Figure 1).

Patients in the QD and BD cohorts were similar demographically with the exception of socioeconomic status, which was higher, thus better, in the QD cohort (Table 1 and supplementary table 1). Asthma control measures differed, however: in the QD cohort, significantly more patients had no loss of asthma control; fewer were prescribed oral corticosteroids; fewer had asthma consultations; and the median ICS doses consumed during the baseline year and prescribed at step-down were lower than in the BD cohort (Table 1).

During the year after step-down, not all patients were prescribed a second controller: $216(42.8 \%)$ and 11,217 (55.2\%) of patients in QD and BD cohorts, respectively, received one or more prescriptions for a LABA (separate or in fixed-dose combination with ICS); $85(16.8 \%)$ and $2424(11.9 \%)$, respectively were prescribed an LTRA. The ICS dose was increased for 240 (47.5\%) of patients in the QD cohort and $9734(47.9 \%)$ of those in the BD cohort. The comparisons between the 
Citation: Price D, Chisholm A, Hillyer EV, Burden A, von Ziegenweidt J, et al. (2013) Effect of Inhaled Corticosteroid Therapy Step-Down and Dosing Regimen on Measures of Asthma Control. J Aller Ther 4: 126. doi:10.4172/2155-6121.1000126

Page 4 of 8

\begin{tabular}{|c|c|c|c|c|c|c|}
\hline \multirow[b]{2}{*}{ Characteristic } & \multicolumn{3}{|c|}{ ICS cohorts $(n=26,834)$} & \multicolumn{3}{|c|}{ ICS/LABA cohorts $(n=20,814)$} \\
\hline & $\begin{array}{c}\text { Switch to QD } \\
(n=941)\end{array}$ & $\begin{array}{c}\text { Remain on BD } \\
(n=25,893)\end{array}$ & p value* & $\begin{array}{c}\text { Switch to QD } \\
(n=505)\end{array}$ & $\begin{array}{c}\text { Remain on BD } \\
(n=20,309)\end{array}$ & p value ${ }^{*}$ \\
\hline Female sex, n (\%) & $498(52.9)$ & $14,250(55.0)$ & 0.201 & $327(64.8)$ & $12,353(60.8)$ & 0.074 \\
\hline Age at index date, median (IQR) & $32(12-49)$ & $26(10-47)$ & $<0.001$ & $44(24-56)$ & $42(24-55)$ & 0.560 \\
\hline $4-11$ years, $\mathrm{n}(\%)$ & $226(24.0)$ & $7994(30.9)$ & $<0.001$ & $55(10.9)$ & $2155(10.6)$ & 0.380 \\
\hline $12-60$ years, $\mathrm{n}(\%)$ & $636(67.6)$ & $16,018(61.9)$ & & $373(73.9)$ & $15,472(76.2)$ & \\
\hline 61-80 years (all nonsmokers), n (\%) & $79(8.4)$ & $1881(7.3)$ & & $77(15.2)$ & $2682(13.2)$ & \\
\hline BMI $\left(\mathrm{kg} / \mathrm{m}^{2}\right)$, mean $(\mathrm{SD}) \dagger$ & $25.2(6.4)$ & $25.1(7.3)$ & 0.164 & $26.8(6.7)$ & $27.1(6.8)$ & 0.238 \\
\hline Underweight $\left(\mathrm{BMI}<18.5 \mathrm{~kg} / \mathrm{m}^{2}\right), \mathrm{n}(\%)$ & $101(14.4)$ & $3242(17.5)$ & 0.193 & $37(8.5)$ & $1316(7.5)$ & 0.719 \\
\hline Normal BMI (18.5-24.49 kg/m²), n (\%) & $257(36.6)$ & $6620(35.7)$ & & $151(34.6)$ & $5843(33.1)$ & \\
\hline Overweight (BMI 25-29.99 kg/m²), n (\%) & $200(28.5)$ & $4955(26.7)$ & & $130(29.7)$ & $5553(31.5)$ & \\
\hline Obese $\left(\mathrm{BMI} \geq 30 \mathrm{~kg} / \mathrm{m}^{2}\right), \mathrm{n}(\%)$ & $144(20.5)$ & $3734(20.1)$ & & $119(27.2)$ & $4942(28.0)$ & \\
\hline Recorded smoking status, n (\%) & $877(93.2)$ & $23,674(91.4)$ & & $484(95.8)$ & 19,721 (97.1) & \\
\hline Current smoker & $181(20.6)$ & $5965(25.2)$ & 0.007 & $103(21.3)$ & $3970(20.1)$ & 0.822 \\
\hline Ex-smoker & $226(25.8)$ & $5496(23.2)$ & & $97(20.0)$ & $4029(20.4)$ & \\
\hline Non-smoker & $470(53.6)$ & $12,213(51.6)$ & & $284(58.7)$ & $11,722(59.4)$ & \\
\hline Socioeconomic status, median (IQR)‡ & $17.7(8.4-41)$ & $17.9(9.4-33.9)$ & 0.438 & $23.4(11.2-42.0)$ & $17.9(8.8-33.0)$ & 0.004 \\
\hline \multicolumn{7}{|l|}{ Recorded comorbidity/treatment, $\mathrm{n}(\%) \S$} \\
\hline Rhinitis & $303(32.2)$ & $8057(31.1)$ & 0.481 & $170(33.7)$ & $6802(33.5)$ & 0.936 \\
\hline Cardiac disease & $187(19.9)$ & $4713(18.2)$ & 0.193 & $141(27.9)$ & $5612(27.6)$ & 0.886 \\
\hline Gastroesophageal reflux disease & $140(14.9)$ & $3213(12.4)$ & 0.024 & $118(23.4)$ & $4690(23.1)$ & 0.886 \\
\hline \multicolumn{7}{|l|}{$\geq 1$ prescription prior 12 months (\%) } \\
\hline NSAID & $138(14.7)$ & $3677(14.2)$ & 0.689 & $119(23.6)$ & $4244(20.9)$ & 0.146 \\
\hline Beta blocker & $16(1.7)$ & $500(1.9)$ & 0.613 & $3(0.6)$ & $343(1.7)$ & 0.057 \\
\hline Acetaminophen & $157(16.7)$ & $5108(19.7)$ & 0.021 & $137(27.1)$ & $5051(24.9)$ & 0.247 \\
\hline Daily ICS dose $(\mu \mathrm{g} / \mathrm{d})$, median (IQR)\| & $164(99-329)$ & $219(110-384)$ & $<0.001$ & $329(164-756)$ & $395(164-822)$ & 0.009 \\
\hline \multicolumn{7}{|l|}{ Mean daily ICS dose, $\mathrm{n}(\%)$} \\
\hline $1-100 \mu \mathrm{g} / \mathrm{d}$ & $245(26)$ & $5216(20.1)$ & $<0.001$ & $81(16.0)$ & $2246(11.1)$ & 0.010 \\
\hline $101-200 \mu \mathrm{g} / \mathrm{d}$ & $275(29.2)$ & $7594(29.3)$ & & $89(17.6)$ & $3597(17.7)$ & \\
\hline $201-400 \mu \mathrm{g} / \mathrm{d}$ & $231(24.5)$ & $6743(26.0)$ & & $108(21.4)$ & $4352(21.4)$ & \\
\hline $401-800 \mu \mathrm{g} / \mathrm{d}$ & $134(14.2)$ & $4361(16.8)$ & & $109(21.6)$ & $4955(24.4)$ & \\
\hline$\geq 801 \mu \mathrm{g} / \mathrm{d}$ & $56(6.0)$ & $1979(7.6)$ & & $118(23.4)$ & $5159(25.4)$ & \\
\hline Concomitant LTRA, n (\%) & $26(2.8)$ & $287(1.1)$ & $<0.001$ & $78(15.4)$ & $1946(9.6)$ & $<0.001$ \\
\hline No. SABA scripts, median (IQR) & $2(1-4)$ & $2(1-4)$ & $<0.001$ & $3(1-5)$ & $3(1-7)$ & $<0.001$ \\
\hline \multicolumn{7}{|l|}{ Mean daily SABA dose, $\mathrm{n}(\%) \|$} \\
\hline $0-100 \mu \mathrm{g} / \mathrm{d}$ & $335(35.6)$ & $7764(30.0)$ & $<0.001$ & $134(26.5)$ & $4386(21.6)$ & $<0.001$ \\
\hline $101-200 \mu \mathrm{g} / \mathrm{d}$ & $260(27.6)$ & $7032(27.2)$ & & $121(24.0)$ & $4022(19.8)$ & \\
\hline $201-400 \mu \mathrm{g} / \mathrm{d}$ & $188(20)$ & $5844(22.6)$ & & $131(25.9)$ & $4980(24.5)$ & \\
\hline$\geq 401 \mu \mathrm{g} / \mathrm{d}$ & $158(16.8)$ & $5253(20.3)$ & & $119(23.6)$ & $6921(34.1)$ & \\
\hline No loss of asthma control, $n(\%) \pi$ & $685(72.8)$ & $17,330(66.9)$ & $<0.001$ & $298(59.0)$ & $11,040(54.4)$ & 0.038 \\
\hline $\begin{array}{l}\text { No loss of asthma control + limited SABA, } \\
n(\%) \pi\end{array}$ & $442(47.0)$ & $10,354(40.0)$ & $<0.001$ & $174(34.5)$ & $5181(25.5)$ & $<0.001$ \\
\hline \multicolumn{7}{|l|}{ Total exacerbations, $\mathrm{n}(\%) \boldsymbol{\pi}$} \\
\hline 0 & $690(73.3)$ & $17,452(67.4)$ & $<0.001$ & $303(60.0)$ & $11,135(54.8)$ & 0.054 \\
\hline 1 & $177(18.8)$ & $5263(20.3)$ & & $102(20.2)$ & $4385(21.6)$ & \\
\hline$\geq 2$ & $74(7.9)$ & $3178(12.3)$ & & $100(19.8)$ & $4789(23.6)$ & \\
\hline \multicolumn{7}{|l|}{ Primary care consultations, n (\%) } \\
\hline $0-3$ & $259(27.5)$ & $6747(26.1)$ & 0.226 & $73(14.5)$ & $3249(16.0)$ & 0.494 \\
\hline $4-5$ & $167(17.7)$ & $4574(17.7)$ & & $78(15.4)$ & $2743(13.5)$ & \\
\hline $6-8$ & $220(23.4)$ & $5625(21.7)$ & & $101(20.0)$ & $4060(20.0)$ & \\
\hline $9-13$ & $166(17.6)$ & $5315(20.5)$ & & $110(21.8)$ & $4829(23.8)$ & \\
\hline$\geq 14$ & $129(13.7)$ & $3632(14.0)$ & & $143(28.3)$ & $5428(26.7)$ & \\
\hline
\end{tabular}

*The Mann-Whitney $U$ test was used to compare continuous variables and the $\mathrm{X} 2$ test, categorical variables.

†Weight and height to calculate BMI were available for 702 (74.6\%) and 18,529 (71.6\%) of patients in ICS QD and BD cohorts, respectively, and 437 (86.5\%) and 17,651 $(86.9 \%)$ of patients in ICS/LABA QD and BD cohorts, respectively.

$\ddagger$ The socioeconomic status is the Index of Multiple Deprivation score linked to each practice postcode.

$\S P a t i e n t s$ with rhinitis, cardiac disease, and GERD included those with a recorded diagnosis or recorded therapy for same.

॥The ICS dose is the beclomethasone dipropionate-equivalent, and the SABA dose is the albuterol equivalent.

TComposite database measure (defined in text).

BD: Twice Daily; BMI: Body Mass Index; ICS: Inhaled Corticosteroid; IQR: Interquartile Range; LABA: Long-Acting $\beta$-Agonist; LTRA: Leukotriene Receptor Antagonist; NSAID: Non-steroidal Anti-Inflammatory Drug; QD: Once Daily; SABA: Short-Acting $\beta$-Agonist

Table 1: Baseline year characteristics of the ICS and ICS/LABA cohorts. 
Citation: Price D, Chisholm A, Hillyer EV, Burden A, von Ziegenweidt J, et al. (2013) Effect of Inhaled Corticosteroid Therapy Step-Down and Dosing Regimen on Measures of Asthma Control. J Aller Ther 4: 126. doi:10.4172/2155-6121.1000126

Page 5 of 8

\begin{tabular}{|c|c|c|c|c|c|c|}
\hline \multirow[b]{2}{*}{ Characteristic } & \multicolumn{3}{|c|}{ ICS cohorts $(n=26,834)$} & \multicolumn{3}{|c|}{ ICS/LABA cohorts $(n=20,814)$} \\
\hline & $\begin{array}{c}\text { Switch to } Q D \\
(n=941)\end{array}$ & $\begin{array}{c}\text { Remain on BD } \\
(n=25,893)\end{array}$ & p value* & $\begin{array}{c}\text { Switch to QD } \\
(n=505)\end{array}$ & $\begin{array}{c}\text { Remain on BD } \\
(n=20,309)\end{array}$ & p value* \\
\hline Year of index prescription, mean (SD) & $2000.8(4.7)$ & $1999.6(4.3)$ & $<0.001$ & $2003.4(3.6)$ & $2003.2(3.3)$ & 0.002 \\
\hline \multicolumn{7}{|l|}{ ICS drug prescribed at the index date } \\
\hline Beclomethasone & $353(37.5)$ & $18,249(70.5)$ & $<0.001$ & $48(9.5)$ & $5474(27.0)$ & $<0.001$ \\
\hline Fluticasone & $130(13.8)$ & $2790(10.8)$ & & $184(36.4)$ & $9309(45.8)$ & \\
\hline Mometasone & $53(5.6)$ & $10(0.0)$ & & $20(4.0)$ & $19(0.1)$ & \\
\hline Budesonide & $272(28.9)$ & $4841(18.7)$ & & $126(25.0)$ & $5495(27.1)$ & \\
\hline Ciclesonide & $133(14.1)$ & $3(0.0)$ & & $127(25.1)$ & $12(0.1)$ & \\
\hline \multicolumn{7}{|c|}{ ICS doset prescribed at the index date, $\mathrm{n}(\%)$} \\
\hline$\leq 200 \mu \mathrm{g} / \mathrm{day}$ & $748(79.5)$ & $13,758(53.1)$ & $<0.001$ & $331(65.5)$ & $5091(25.1)$ & $<0.001$ \\
\hline $201-400 \mu \mathrm{g} /$ day & $145(15.4)$ & $10,100(39.0)$ & & $75(14.9)$ & $8827(43.5)$ & \\
\hline$>400 \mu \mathrm{g} /$ day & $48(5.1)$ & $2035(7.9)$ & & $99(19.6)$ & $6391(31.5)$ & \\
\hline \multicolumn{7}{|l|}{ Percentage step-down in ICS dose, n (\%) } \\
\hline $50 \%$ & $493(52.4)$ & $20,093(77.6)$ & $<0.001$ & $237(46.9)$ & $12,079(59.5)$ & $<0.001$ \\
\hline$>50 \%$ & $448(47.6)$ & $5800(22.4)$ & & $268(53.1)$ & $8230(40.5)$ & \\
\hline
\end{tabular}

${ }^{*} X^{2}$ test; $†$ The ICS dose is the beclomethasone dipropionate-equivalent.

BD: Twice Daily; ICS: Inhaled Corticosteroid; LABA: Long-Acting $\beta$-Agonist; QD: Once Daily

Table 2: Inhaled corticosteroid drug and dose prescribed on the index date when patients were stepped down by $\geq 50 \%$ in ICS dose

\begin{tabular}{|c|c|c|c|c|c|c|}
\hline \multirow[b]{3}{*}{ Characteristic } & \multicolumn{6}{|c|}{ ICS cohorts } \\
\hline & \multicolumn{3}{|c|}{ QD cohort $(n=941)$} & \multicolumn{3}{|c|}{ BD cohort $(n=25,893)$} \\
\hline & Baseline year & Year after step-down & $p$ value & Baseline year & Year after step-down & $\mathrm{p}$ value \\
\hline No consultation for LRTI, n (\%) & $803(85.3)$ & $845(89.8)$ & $0.002 \ddagger$ & $21,409(82.7)$ & $22,709(87.7)$ & $<0.001 \ddagger$ \\
\hline Daily ICS dose $(\mu \mathrm{g} / \mathrm{d})$, median (IQR) & $164(99-329)$ & $219(137-384)$ & $<0.001^{*}$ & $219(110-384)$ & $274(164-493)$ & $<0.001^{*}$ \\
\hline ICS adherence $\geq 70 \%, \mathrm{n}(\%)$ & $440(46.8)$ & $710(75.5)$ & $<0.001 \dagger$ & $13,495(52.1)$ & $16,184(62.5)$ & $<0.001 \dagger$ \\
\hline Spacer device used, n (\%) & $106(11.3)$ & $71(7.5)$ & $0.003 \ddagger$ & $4630(17.9)$ & $3221(12.4)$ & $<0.001 \ddagger$ \\
\hline Daily SABA dose $(\mu \mathrm{g} / \mathrm{d})$, median (IQR) & $110(55-274)$ & $164(55-329)$ & $<0.001^{*}$ & $164(55-329)$ & $219(110-438)$ & $<0.001^{*}$ \\
\hline \multirow[t]{3}{*}{ Controller: total asthma med ratio, mean (SD) } & $0.58(0.25)$ & $0.60(0.20)$ & $<0.001^{*}$ & $0.54(0.24)$ & $0.60(0.20)$ & $<0.001^{*}$ \\
\hline & \multicolumn{6}{|c|}{ ICS/LABA cohorts } \\
\hline & \multicolumn{3}{|c|}{ QD cohort $(n=505)$} & \multicolumn{3}{|c|}{ BD cohort $(n=20,309)$} \\
\hline No consultation for LRTI, n (\%) & $406(80.4)$ & $419(83.0)$ & $0.287 \ddagger$ & $15,939(78.5)$ & $16,796(82.7)$ & $<0.001 \ddagger$ \\
\hline Daily ICS dose $(\mu \mathrm{g} / \mathrm{d})$, median (IQR) & $329(164-756)$ & $362(210-712)$ & $0.280^{*}$ & $395(164-822)$ & $460(247-855)$ & $<0.001^{*}$ \\
\hline ICS adherence $\geq 70 \%, \mathrm{n}(\%)$ & $297(58.8)$ & $399(79.0)$ & $<0.001 \dagger$ & $13,019(64.1)$ & $13,731(67.6)$ & $<0.001 \dagger$ \\
\hline Spacer device used, n (\%) & $70(13.9)$ & $69(13.7)$ & $1.0 \ddagger$ & 3975 (19.6) & $2799(13.8)$ & $<0.001 \ddagger$ \\
\hline Daily SABA dose $(\mu \mathrm{g} / \mathrm{d})$, median (IQR) & $186(55-384)$ & $219(110-438)$ & $0.086^{*}$ & $219(110-548)$ & $219(110-548)$ & $0.001^{*}$ \\
\hline Controller: total asthma med ratio, mean (SD) & $0.60(0.26)$ & $0.60(0.20)$ & $0.002^{*}$ & $0.54(0.27)$ & $0.60(0.20)$ & $<0.001^{*}$ \\
\hline
\end{tabular}

*Wilcoxon signed rank test; †marginal homogeneity test; $\ddagger$ McNemar test

BD: Twice Daily; IQR: Interquartile Range; LABA: Long-Acting $\beta$-Agonist; LRTI: Lower Respiratory Tract Infection; QD: Once Daily; SABA: Short-Acting $\beta$-Agonist

Table 3: Baseline year measures vs. the year after step-down in inhaled corticosteroid (ICS) dose.

baseline year and the year after step-down resembled those for patients in the ICS population: in both QD and BD cohorts, the proportions of patients with no exacerbations; no GP consultations for LRTI; no asthma consultations, and only 0-3 primary care consultations were significantly higher in the year after ICS dose step-down, as compared with baseline (Figure 2 and table 3 ). The proportion of patients with no loss of asthma control increased from baseline but not significantly in the QD cohort, while in the BD cohort the proportion increased significantly from baseline for both asthma control measures (Figure 2 ). Adherence improved after step-down for both cohorts, resulting in significantly higher consumed ICS daily dose in the BD cohort despite the prescribed step-down (Table 3). Increased adherence was most marked in patients stepped down to QD therapy.

Baseline factors that predicted a loss of asthma control in the year after ICS dose step-down for patients who had no loss of asthma control during the baseline year are listed in table 5. Older patients, those with an earlier step-down date, those with recorded rhinitis or GERD, those who received acetaminophen, and those who received two or more
SABA prescriptions during the baseline year were more likely to lose asthma control, as were patients who had more than three primary care consultations or consumed ICS $>800 \mu \mathrm{g} /$ day during the baseline year. As for the ICS population, the dosing regimen after step-down (QD vs. $\mathrm{BD})$ was not a predictive factor for loss of asthma control.

\section{Discussion}

The results of this real-life observational study indicate that stepping down ICS dose is a valid management option and may improve asthmarelated outcomes in the UK primary care setting. Patients in both ICS and ICS/LABA cohorts showed significant improvements in most database markers of asthma control during the year after step-down, as compared with the baseline year. Moreover, we found that adherence to controller therapy improved significantly in all treatment cohorts after step-down. Improvements were recorded in asthma control markers and adherence irrespective of whether patients were stepped down from the $\mathrm{BD}$ baseline regimen to a $\mathrm{QD}$ or $\mathrm{BD}$ frequency of administration during the year after step-down. 
Citation: Price D, Chisholm A, Hillyer EV, Burden A, von Ziegenweidt J, et al. (2013) Effect of Inhaled Corticosteroid Therapy Step-Down and Dosing Regimen on Measures of Asthma Control. J Aller Ther 4: 126. doi:10.4172/2155-6121.1000126

Page 6 of 8
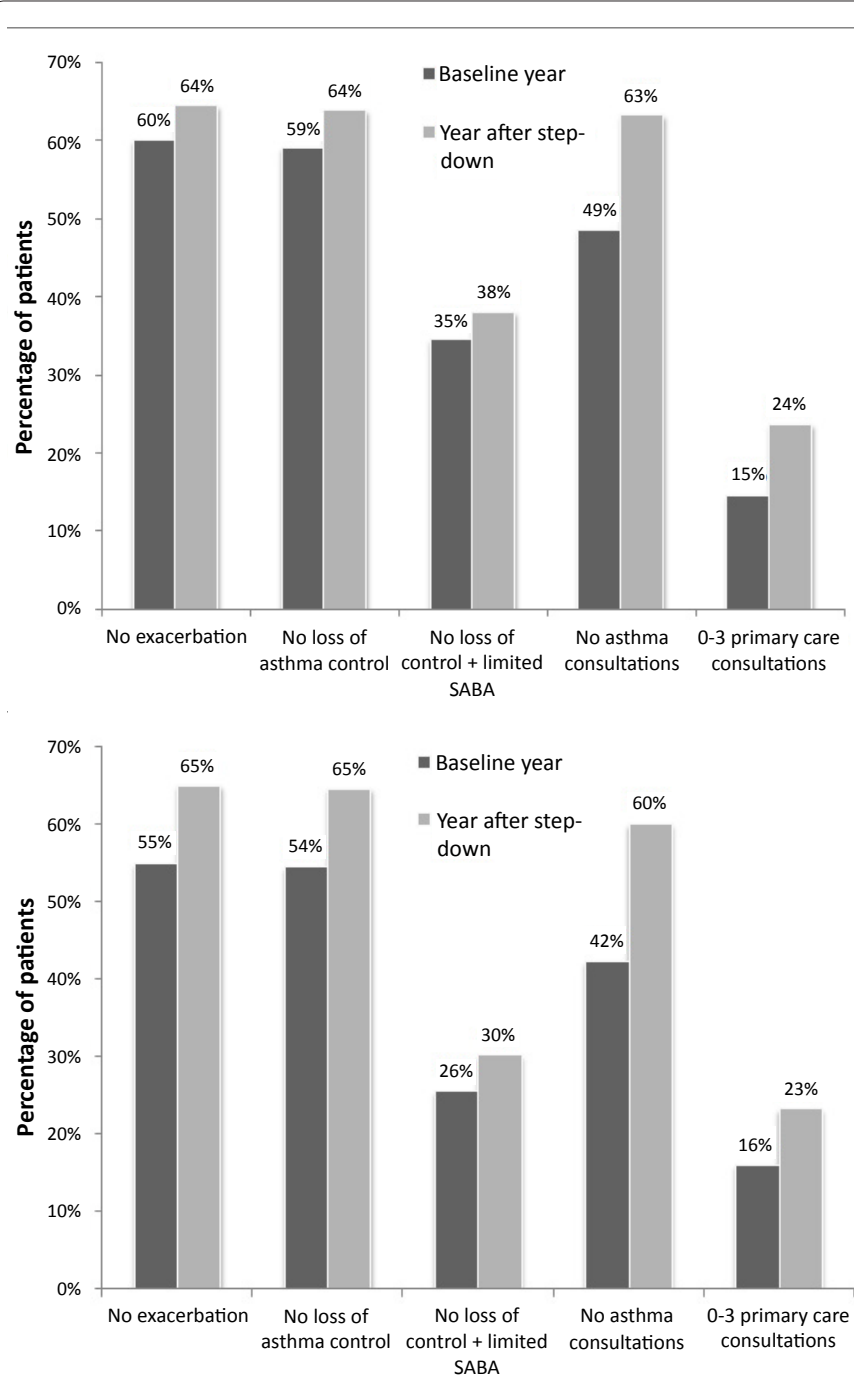

Figure 2: Asthma-related measures for the ICS/LABA cohorts during the baseline year and the year after step-down in ICS dose to a once-daily regimen $(A)$ or a twice-daily regimen $(B)$. In the $Q D$ cohort, the number of exacerbations and asthma and primary care consultations decreased significantly between baseline and post step-down $(p \leq 0.04)$. In the BD cohort, all measures improved significantly between baseline and post stepdown $(p<0.001)$.

Drawing retrospectively on two similarly structured databases enabled us to characterize and examine real-life outcomes for over 47,000 patients who had received usual care for asthma at UK primary care practices. Following patients for 2 full years enabled us to examine clinical characteristics over the baseline year before step-down in addition to database measures of asthma control over a full year after step-down, thereby eliminating the influence of seasonal variations in asthma symptoms. These findings provide descriptive information on the use of management options that are recommended in best practice guidelines but remain poorly understood. Interestingly, despite the large patient numbers, our study population represents a small proportion of patients in the CPRD and OPCRD who are receiving ICS for asthma, suggesting that ICS dose is not frequently stepped down.

This study does not provide information on the deciding factors for step-down, namely, precisely why prescribing physicians decided to decrease ICS dose by $\geq 50 \%$. Over the course of the baseline year,

\begin{tabular}{|c|l|c|}
\hline Category & Odds Ratio (95\% Cl) & P value \\
\hline Normal BMI $\left(18.5-24.49 \mathrm{~m} / \mathrm{kg}^{2}\right)$ & 1.00 & \\
\hline vs. Underweight $\left(<18.5 \mathrm{~m} / \mathrm{kg}^{2}\right)$ & $1.05(0.90-1.22)$ & 0.010 \\
\hline vs. Overweight $\left(25-29.99 \mathrm{~m} / \mathrm{kg}^{2}\right)$ & $1.12(0.99-1.26)$ & \\
\hline vs. Obese $\left(\geq 30 \mathrm{~m} / \mathrm{kg}^{2}\right)$ & $1.25(1.10-1.42)$ & \\
\hline Female & 1.00 & 0.002 \\
\hline vs. Male & $0.85(0.77-0.95)$ & \\
\hline Non-smoker & 1.00 & 0.005 \\
\hline vs. Current smoker & $1.13(1.002-1.28)$ & \\
\hline vs. Ex-smoker & $0.91(0.80-1.03)$ & \\
\hline Year of step-down date (later vs. earlier) & $0.88(0.84-0.93)$ & $<0.001$ \\
\hline No GERD diagnosis and/or drugs & 1.00 & $<0.001$ \\
\hline vs. GERD diagnosis and/or drugs & $1.39(1.23-1.58)$ & \\
\hline $0-1$ SABA prescriptions/year & 1.00 & $<0.001$ \\
\hline vs. 2-3/year & $1.03(0.92-1.16)$ & \\
\hline vs. 4-6/year & $1.14(0.996-1.31)$ & \\
\hline vs. $\geq 7 /$ year & $1.41(1.22-1.62)$ & \\
\hline $0-3$ primary care consultations/year & 1.00 & $<0.001$ \\
\hline vs. 4-5/year & $1.27(1.09-1.47)$ & \\
\hline vs. 6-8/year & $1.31(1.14-1.52)$ & \\
\hline vs. 9-13/year & $1.73(1.49-1.99)$ & \\
\hline vs. $\geq 14 /$ year & $1.82(1.55-2.14)$ & \\
\hline
\end{tabular}

${ }^{*}$ Composite database measure (defined in text)

BMI: Body Mass Index; GERD: Gastroesophageal Reflux Disease; ICS: Inhaled Corticosteroid; SABA: Short-acting $\beta$-Agonist

Table 4: Demographic and baseline factors predictive of loss of asthma control during the year after ICS dose step-down for all patients in the ICS cohorts who me the composite database measure of no loss of asthma control ${ }^{*}$ during the baseline year $(n=18,015)$ : A multivariate model.

\begin{tabular}{|c|c|c|}
\hline Category & Odds Ratio $(95 \% \mathrm{CI})$ & $p$ value \\
\hline Age (older vs. younger) & $1.01(1.00-1.01)$ & $<0.001$ \\
\hline Year of step-down date (later vs. earlier) & $0.89(0.83-0.95)$ & $<0.001$ \\
\hline No rhinitis diagnosis and/or drugs & 1.00 & 0.001 \\
\hline vs. rhinitis diagnosis and/or drugs & $1.18(1.07-1.30)$ & \\
\hline No GERD diagnosis and/or drugs & 1.00 & $<0.001$ \\
\hline vs. GERD diagnosis and/or drugs & $1.27(1.13-1.42)$ & \\
\hline No acetaminophen prescription & 1.00 & $<0.001$ \\
\hline vs. yes acetaminophen prescription & $1.20(1.07-1.34)$ & \\
\hline 0-1 SABA prescriptions/year & 1.00 & $<0.001$ \\
\hline vs. 2-3/year & $1.17(1.02-1.34)$ & \\
\hline vs. 4-6/year & $1.27(1.11-1.46)$ & \\
\hline vs. $\geq 7 /$ year & $1.46(1.29-1.66)$ & \\
\hline ICS dose $1-100 \mu \mathrm{g} /$ day & 1.00 & 0.031 \\
\hline vs. $101-200 \mu \mathrm{g} /$ day & $1.10(0.92-1.31)$ & \\
\hline vs. $201-400 \mu \mathrm{g} / \mathrm{day}$ & $0.995(0.84-1.18)$ & \\
\hline vs. $401-800 \mu \mathrm{g} / \mathrm{day}$ & $1.16(0.99-1.37)$ & \\
\hline vs. $>800 \mu \mathrm{g} /$ day & $1.21(1.02-1.43)$ & \\
\hline 0-3 primary care consultations/year & 1.00 & $<0.001$ \\
\hline vs. 4-5/year & $1.41(1.20-1.65)$ & \\
\hline vs. 6-8/year & $1.61(1.39-1.87)$ & \\
\hline vs. 9-13/year & $1.83(1.58-2.12)$ & \\
\hline vs. $\geq 14 /$ year & $1.92(1.65-2.24)$ & \\
\hline
\end{tabular}

*See text for definition.

GERD: Gastroesophageal Reflux Disease; ICS: Inhaled Corticosteroid; LABA Long-Acting $\beta$-Agonist; SABA: Short-Acting $\beta$-Agonist

Table 5: Demographic and baseline factors predictive of loss of asthma contro during the year after ICS dose step-down for all patients in the ICS/LABA cohorts who met the composite database measure of no loss of asthma control* during the baseline year $(n=11,338)$ : A multivariate model.

only $67 \%$ and $55 \%$ of patients in ICS and ICS/LABA populations, respectively, met the database measure of no loss of asthma control; and the percentages of patients who met the more stringent asthma control measure limiting SABA use were even lower (40\% and $26 \%$, 
respectively). Presumably, therefore, all patients were doing well during the period immediately preceding the step-down date even if their asthma was not well-controlled during the entire baseline year. A study limitation is that our retrospective assessments of asthma control necessarily are restricted to recorded data such as consultations, hospitalizations, and prescriptions and do not include either subjective measures, such as patient-reported quality of life, or objective measures that are infrequently recorded in primary care, such as lung function and inflammatory markers.

Several small studies have found that lung function tests and parameters of airway inflammation, particularly sputum eosinophil count, can be useful for individualizing step-down strategies and monitoring patients [16-20]; these tests, however, may be impractical in the primary care setting where most patients with asthma are managed [21]. In a recent study, Clearie et al. [17] were able to significantly step down ICS dose for 119 of 150 (79\%) community-based patients without any worsening of airways inflammation or lung function. They hypothesized that successful step-down may be the result of enhanced adherence because of the supervised step-down.

We also found improved adherence after step-down and speculate that a similar mechanism could be operative in our study. Patients may better accept their asthma care and better self-regulate if they are involved in the decision to step down dose. Adherence improved most dramatically in the QD cohorts-to $\geq 70 \%$ for more than three quarters of patients-perhaps because of a simplified dosing regimen. Indeed one could argue that we detected a step-up effect, since the median consumed dose of ICS increased during the year after the prescribed step-down in dose. An explanation for this finding could be that there was better patient supervision during the step-down process, which, if true, would indicate that better patient supervision can result in improved asthma control.

For patients on combination therapy with ICS/LABA, the results of several studies suggest that asthma control is better maintained if the ICS dose is tapered while LABA is continued [5,22-24]. By contrast, in the Clearie et al. study [17], 18 of 21 patients receiving concomitant LABA were able to discontinue it successfully before tapering ICS. Their study procedure was to discontinue concomitant controller therapy (eg, LABA) and then halve the ICS dose every 2 weeks until patients became unstable or reached a BDP-equivalent dose of $\leq 200 \mu \mathrm{g} /$ day; patients whose asthma became unstable stepped back up to the last stable dose of ICS. In our study, $6.5 \%$ of patients in the ICS cohorts were prescribed a LABA, and $2 \%$ were prescribed an LTRA, during the year after stepdown; in the ICS/LABA cohorts, $55 \%$ and $12 \%$ were prescribed a LABA or an LTRA, respectively, after step-down.

This study identified several factors predictive of loss of asthma control after step-down for previously controlled patients. Most of the factors we identified are considered to be either risk factors for or indicators of poor asthma control [1-3,25-27]. Predictive factors common to both ICS and ICS/LABA populations were comorbid GERD and, during the baseline year, seven or more SABA prescriptions and four or more primary care consultations. In the ICS cohort, an earlier index date (or longer asthma duration), female sex, obesity, and smoking also significantly raised the odds of loss of asthma control after step-down; in the ICS/LABA population, additional significant factors were older age, comorbid rhinitis, and, during the baseline year, a prescription for acetaminophen or mean consumed ICS dose of $>800 \mu \mathrm{g} /$ day. These factors are important clinically and consistent with previous research especially for rhinitis, high SABA use, and acetaminophen, as they could be considered markers of patients at risk of poor outcomes and who may require closer monitoring and clinical attention [25-27]. Further research is needed to examine outcomes for these patients after step-down in ICS dose. A prior study found that for patients with mild asthma who discontinue controller therapy, older age and longer asthma duration were the best predictors of symptom recurrence [28].

We did not compare results for patients in the QD and BD cohorts as this was not part of our a priori analysis plan; however, improvements in asthma control and adherence were numerically similar for QD and $\mathrm{BD}$ cohorts in the year after step-down. Moreover, the regimen after step-down (QD vs. BD) was not a predictive factor for loss of asthma control. However, patients who were stepped down to a QD regimen represented a small proportion of studied patients $3.5 \%$ and $2.4 \%$ of ICS and ICS/LABA populations, respectively). The baseline data suggest that for both ICS and ICS/LABA populations, asthma was generally better controlled at baseline in patients stepped down to QD rather than BD administration. Moreover, in the ICS population, patients in the QD cohort were older and less likely to smoke than those in the $\mathrm{BD}$ cohort; in the ICS/LABA population, socioeconomic status was the only demographic difference between cohorts (higher SES in the QD cohort).

In conclusion, the results of this study suggest that stepping down therapy is a valid management option and may improve asthma-related outcomes. Stepping down therapy from a BD to a QD regimen does not lead to loss of asthma control. The improvements seen in our study may be the result of increased adherence, particularly among patients switched to QD therapy. Additional larger studies are required to understand for which patients, and when, to step down existing therapy.

\section{References}

1. British Thoracic Society, Scottish Intercollegiate Guidelines Network (2012) British Guideline on the Management of Asthma. A national clinical guideline. [http://www.sign.ac.uk/guidelines/fulltext/101/index.html].

2. Global Initiative for Asthma (GINA) (2011) GINA Report, Global Strategy for Asthma Management and Prevention. [http://www.ginasthma.org/].

3. National Asthma Education and Prevention Program Expert Panel Report 3 (2007) Guidelines for the Diagnosis and Management of Asthma. Nationa Heart, Lung, and Blood Institute, National Institutes of Health. [http://www.nhlbi. nih.gov/guidelines/asthma/asthgdln.pdf].

4. Bacharier LB (2012) Step-down therapy in asthma: a focus on treatment options for patients receiving inhaled corticosteroids and long-acting betaagonist combination therapy. Allergy Asthma Proc 33: 13-18.

5. Rogers L, Reibman J (2012) Stepping down asthma treatment: how and when Curr Opin Pulm Med 18: 70-75.

6. Ingersoll KS, Cohen $\mathrm{J}(2008)$ The impact of medication regimen factors on adherence to chronic treatment: a review of literature. J Behav Med 31: 213 224

7. Price D, Robertson A, Bullen K, Rand C, Horne R, et al. (2010) Improved adherence with once-daily versus twice-daily dosing of mometasone furoate administered via a dry powder inhaler: a randomized open-label study. BMC Pulm Med 10: 1

8. Clinical Practice Research Datalink (2012). [http://www.cprd.com/home/].

9. Hansell A, Hollowell J, Nichols T, McNiece R, Strachan D (1999) Use of the General Practice Research Database (GPRD) for respiratory epidemiology: a comparison with the 4th Morbidity Survey in General Practice (MSGP4). Thorax 54: 413-419.

10. Jick SS, Kaye JA Vasilakis-Scaramozza C, Garcia Rodriguez LA, Ruigomez A, et al. (2003) Validity of the General Practice Research Database. Pharmacotherapy 23: 686-689.

11. Price D, Martin RJ, Barnes N, Dorinsky P, Israel E, et al. (2010) Prescribing practices and asthma control with hydrofluoroalkane-beclomethasone and fluticasone: a real-world observational study. J Allergy Clin Immunol 126: 511-518. 
Citation: Price D, Chisholm A, Hillyer EV, Burden A, von Ziegenweidt J, et al. (2013) Effect of Inhaled Corticosteroid Therapy Step-Down and Dosing Regimen on Measures of Asthma Control. J Aller Ther 4:0126. doi:10.4172/2155-6121.1000126

12. Optimum Patient Care. [http://www.optimumpatientcare.org/].

13. Reddel HK, Taylor DR, Bateman ED, Boulet LP, Boushey HA, et al. (2009) An official American Thoracic Society/European Respiratory Society statement: asthma control and exacerbations: standardizing endpoints for clinical asthma trials and clinical practice. Am J Respir Crit Care Med 180: 59-99.

14. Broder MS, Gutierrez B, Chang E, Meddis D, Schatz M (2010) Ratio of controller to total asthma medications: determinants of the measure. Am J Manag Care 16: 170-178.

15. Schatz M, Zeiger RS, Vollmer WM, Mosen D, Mendoza G, et al. (2006) The controller-to-total asthma medication ratio is associated with patient-centered as well as utilization outcomes. Chest 130: 43-50.

16. McKinlay L, Williamson PA, Short PM, Fardon TC, Lipworth BJ (2011) Proof of concept study to evaluate step-down therapy with inhaled corticosteroid alone or additive therapy on surrogate inflammatory markers in asthma. $\mathrm{Br} \mathrm{J}$ Clin Pharmacol 71: 128-131.

17. Clearie $\mathrm{KL}$, Jackson $\mathrm{CM}$, Fardon TC, Williamson PA, Vaidyanathan $\mathrm{S}$, et al. (2011) Supervised step-down of inhaled corticosteroids in the community--an observational study. Respir Med 105: 558-565

18. Li AM, Tsang TW, Lam HS, Sung RY, Chang AB (2008) Predictors for failed dose reduction of inhaled corticosteroids in childhood asthma. Respirology 13: 400-407.

19. Belda J, Parameswaran K, Lemiere C, Kamada D, O'Byrne PM, et al. (2006) Predictors of loss of asthma control induced by corticosteroid withdrawal. Can Respir J 13: 129-133.

20. Leuppi JD, Salome CM, Jenkins CR, Anderson SD, Xuan W, et al. (2001) Predictive markers of asthma exacerbation during stepwise dose reduction of inhaled corticosteroids. Am J Respir Crit Care Med 163: 406-412.
21. Petsky HL, Cates CJ, Lasserson TJ, Li AM, Turner C, et al. (2012) A systematic review and meta-analysis: tailoring asthma treatment on eosinophilic markers (exhaled nitric oxide or sputum eosinophils). Thorax 67: 199-208.

22. Berger WE, Bleecker ER, O'Dowd L, Miller CJ, Mezzanotte W (2010) Efficacy and safety of budesonide/formoterol pressurized metered-dose inhaler: randomized controlled trial comparing once- and twice-daily dosing in patients with asthma. Allergy Asthma Proc 31: 49-59.

23. Hagiwara M, Delea TE, Stanford RH, Stempel DA (2010) Stepping down to fluticasone propionate or a lower dose of fluticasone propionate/salmetero combination in asthma patients recently initiating combination therapy. Allergy Asthma Proc 31: 203-210.

24. Reddel HK, Gibson PG, Peters MJ, Wark PA, Sand IB, et al. (2010) Downtitration from high-dose combination therapy in asthma: Removal of long-acting beta(2)-agonist. Respir Med 104: 1110-1120.

25. Schatz M, Zeiger RS (2011) Improving asthma outcomes in large populations J Allergy Clin Immunol 128: 273-277.

26. Thomas M, Price D (2008) Impact of comorbidities on asthma. Expert Rev Clin Immunol 4: 731-742.

27. Clatworthy J, Price D, Ryan D, Haughney J, Horne R (2009) The value of selfreport assessment of adherence, rhinitis and smoking in relation to asthma control. Prim Care Respir J 18: 300-305.

28. Tonelli M, Bacci E, Dente FL, Bartoli ML, Cianchetti S, et al. (2006) Predictors of symptom recurrence after low-dose inhaled corticosteroid cessation in mild persistent asthma. Respir Med 100: 622-629. 